\title{
ANÁLISE E DIAGNÓSTICO POSTURAL DO NOVO MODELO DE CARTEIRAS ESCOLARES OFERECIDO AO CURSO DE DESIGN DE UMA UNIVERSIDADE DO INTERIOR DE PERNAMBUCO
}

\section{ANALYSIS AND POSTURAL DIAGNOSIS OF THE NEW MODEL OF SCHOLAR CARTRIDGES OFFERED TO THE DESIGN COURSE OF A UNIVERSITY OF INTERIOR OF PERNAMBUCO}

\author{
John Lenon Gonçalves da Silva ${ }^{1}$, Bacharelando. \\ Bruno Xavier da Silva Barros², M.Sc. \\ (1) Universidade Federal de Pernambuco \\ e-mail: johndesigner@outlook.com \\ (2) Universidade Federal de Pernambuco \\ e-mail:barros_bruno@hotmail.com
}

Palavras-chave: Ergonomia em sala de aula, Postura corporal, Carteiras Escolares.

\begin{abstract}
No Brasil, o enorme quantitativo de universidades demandam do aluno um considerável tempo de uso da carteira escolar na atividade de assistir aula. Este constante uso das carteiras escolares foi um dos pontos de partida para a pesquisa, a qual considerou a verificação da postura imposta pelo novo modelo de carteiras escolares de uma instituição pública de ensino superior. Acreditou-se que, ao fazer a aquisição de um novo modelo de carteiras sem a utilização da Ergonomia como princípio, as carteiras ofereceriam riscos à saúde dos alunos. Desta forma, lançamos mão do método REBA (Rapid Entire Body Assesment) para identificar problemas relacionados à adoção de posturas inadequadas pelos alunos ao utilizarem as carteiras.
\end{abstract}

Key-words: Ergonomics in classrooms Body posture School Wallets.

In Brazil, the enormous amount of universities demand of the student a considerable time of use of the school portfolio in the activity of attending class. This constant use of the school portfolios was one of the starting points for the research, which considered the verification of the posture imposed by the new model of school portfolios of a public institution of higher education. It was believed that by acquiring a new model of portfolios without the use of Ergonomics as a principle, portfolios would pose risks to the health of students. In this way, we use the Rapid Entire Body Assesment (REBA) method to identify problems related to the adoption of inappropriate postures by students when using the portfolios.

\section{Introdução}

Ao longo da história se estruturaram várias evoluções das carteiras escolares, e grandes variações entre os modelos, cada uma com suas características particulares, para atender as 


\section{$16^{\circ}$ \\ ERGODESIGN USIHC CINAHPA}

$16^{\circ}$ Ergodesign - Congresso Internacional de Ergonomia e Usabilidade de Interfaces Humano Tecnológica: Produto, Informações Ambientes Construídos e Transporte

$16^{\circ}$ USIHC - Congresso Internacional de Ergonomia e Usabilidade de Interfaces Humano Computador

CINAHPA | 2017 - Congresso Internacional de Ambientes Hipermídia para Aprendizagem. necessidades econômicas, sociais, culturais, regionais, políticas entre outras. O início da escola cristã, até o início do Século XX, caracterizou-se pela ocupação coletiva das salas de aula, ou seja, uma grande bancada em conjunto com o banco. Os mais modernos já dispunham de base emborrachada, com marcação de lugar individual nos bancos e tinteiro. A Carteira no Brasil surge como uma inovação, na qual se observa a preocupação com a postura e layout da sala. $\mathrm{Na}$ atualidade, no Brasil, a estrutura tubular metálica é combinada com madeira, mas existem também combinações com plástico injetado e, na maioria dos casos, estofamento com espuma e tecido.

O mobiliário escolar tem uma importância fundamental na vida de um estudante, a utilização de carteiras inadequadas do ponto de vista ergonômico pode causar diversos constrangimentos posturais. $\mathrm{O}$ intuito desta pesquisa foi o de verificar se o novo modelo de carteiras oferecido por uma Universidade do interior de Pernambuco causa lesões e danos osteomioarticulares aos estudantes, uma vez que tal modelo não foi escolhido sob a consideração de critérios ergonômicos de seleção.

\section{Fundamentação teórica}

\subsection{Estudo da postura corporal}

Conforme Kendall et al., (2007), a postura corporal é manifestada como o arranjo circunstancial dos segmentos corporais. Ele segue ratificando que para ser considerada uma boa postura é preciso um estado de equilíbrio muscular e esquelético que preserva as estruturas de sustentação do corpo contra lesões e deformidades gradativas, independentemente da posição que as estruturas permanecem, se está trabalhando ou repousando.

De acordo com marques, Hallal e Gonçalves (2010), algumas medidas podem ser executadas para restringir o impacto ao sentar no sistema musculoesquelético, uma das medidas a serem tomadas são as alterações no mobiliário universitário, pois ele interfere no preceito da posição sentada, e essas alterações permitem adoção de várias posturas.

Iida (2005) relata que o conforto é uma sensação muito subjetiva, produzida quando não há nenhum tipo de pressão localizada sobre o corpo. Os autores Chaffin, Andersson e Martin (2006), elucidam que o conforto não pode existir se $o$ desconforto estiver manifesto em qualquer área do corpo ao assumir uma posição.

\subsection{A postura corporal em salas de aula}

De acordo com Nunes et al., (1985) o homem atual pode passar em média um terço do tempo de sua vida na posição sentada. Por esse motivo, o mobiliário deve atender as necessidades dos usuários, para assim proporcionar um maior conforto. Ao sentar, Couto (1995) declara que a primeira alteração que acomete o corpo é o aumento em cerca de $50 \%$ na pressão dos discos intervertebrais da coluna lombar, levando a disposição de degeneração dos discos que tem como função o amortecimento de pressões e sustentação de peso.

A sala de aula universitária requer dos alunos uma atividade estática, e Iida (2005), relata que no trabalho estático há uma maior contração contínua de alguns músculos para conseguir manter por um período de tempo uma determinada posição, sendo assim extremamente fatigante. Segundo Braccialli (1997), o período escolar pode ser indicado como a fase inicial que ajuda a desenvolver vários problemas degenerativos da coluna vertebral dos seres humanos na fase adulta.

Sanoff (2001) relata que o ambiente que constituí a sala de aula, colabora para facilitar a aprendizagem caso seja desenvolvido com cuidado, buscando atender as necessidades dos usuários como professores e alunos. Zabalza (2001) afirma que a sala de aula ou o espaço físico poderá ajudar ou impossibilitar a aquisição da aprendizagem, podendo ser altamente estimulante ou limitador. A forma em que o mobiliário está disposto pode interferir no tempo de aprendizagem dos alunos (RICHARDSON, 1997). 
$16^{\circ}$ Ergodesign - Congresso Internacional de Ergonomia e Usabilidade de Interfaces Humano Tecnológica: Produto, Informações Ambientes Construídos e Transporte

$16^{\circ}$ USIHC - Congresso Internacional de Ergonomia e Usabilidade de Interfaces Humano Computador

CINAHPA | 2017 - Congresso Internacional de Ambientes Hipermídia para Aprendizagem.

Do ponto de vista de Bergmiller et al (1999), é recomendado que se tenha a adoção de tamanhos diferentes de carteiras, para que assim possa ser atendido os requisitos básicos da postura, ao realizar as atividades em sala de aula. Em concordância com a autora, Repuano Guidalli (2012) cita que é recomendado num mesmo ambiente possam ser ofertados mobiliários diferentes, para assim poder permitir uma variação de arranjos, assim podendo deixar a opção de escolha do aluno o mobiliário que mais lhe satisfaz e proporciona conforto. Segundo Carvalho (2001), carteiras desenvolvidas de maneira inadequada podem induzir os usuários a adquirirem posturas erradas, podendo assim gerar problemas na coluna, e nos membros inferiores, como dificuldade na circulação e aumento de compressão na parte posterior da coxa.

Thariq, Munasinghe e Abeysekara (2010), alegam que pouquíssima atenção tem sido oferecida a um desenvolvimento de um desenho ergonômico correto de carteiras escolares com prancheta acoplada. Segundo Repuano Guidalli (2012) dentre outros modelos de carteiras, a que é mais usual é a carteira de braço, com prancheta acoplada. A autora afirma que este modelo, em suma, desagrada os alunos, pela falta de conforto e má funcionalidade.

\section{Procedimento metodológico adotado}

Em termos de aspecto geral, a corrente pesquisa apresenta características do Método Indutivo, o qual se fundamenta na análise de um caso específico e possíveis generalizações dos seus resultados. Como método de procedimento, lançouse mão do Método REBA, o qual orienta o avaliador sobre a necessidade ou não de planejar ações corretivas sobre determinadas posturas (DIEGO-MÁS e CUESTA, 2007). Este método engloba a análise de posturas imprevisíveis de corpo inteiro. Além de analisar o trabalho repetitivo e a força muscular, seu diferencial é que permite analisar tanto as posturas estáticas quanto as dinâmicas.
Foram analisados 22 alunos utilizando as carteiras escolares, sendo 9 do gênero masculino e 11 do gênero feminino, com idades que variaram entre 20 a 42 anos, estaturas entre $1,47 \mathrm{~m}$ a $1,85 \mathrm{~m}$, e peso corporal entre $47 \mathrm{~kg}$ a $88 \mathrm{~kg}$. Foram analisados 16 alunos destros e 4 alunos canhotos todos do turno noturno.

\subsection{Apresentação do estudo de caso}

$\mathrm{Na}$ Universidade pesquisada, a carteira universitária, a qual está substituindo aos poucos o modelo anterior, é composta por prancheta lateral (feita em madeira compensada e revestida de laminado fosco branco), assento e encosto (feitos em resina plástica de alta resistência e de alta durabilidade, na cor azul). $\mathrm{O}$ artefato possui uma estrutura de aço com pintura epóxi em pó na cor cinza claro, sua estrutura metálica fixada na madeira através de rebites e parafusos e a junção das partes metálicas feitas por meio de solda eletrônica mig. Esse novo modelo de carteiras está substituindo o modelo antigo de carteiras oferecido pelo campus.

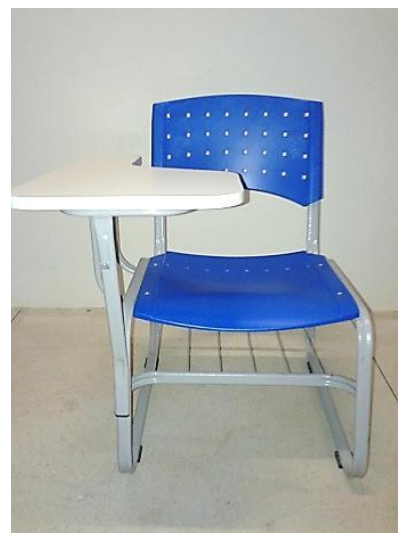

Figura 1: Modelo de carteira analisado.

Fonte: Capturado pelo autor para pesquisa.

O novo modelo de carteiras da universidade tem medidas bastante diferentes do modelo anterior. A seguir, na figura 9 abaixo, veremos o desenho técnico com todas as dimensões especificadas. 


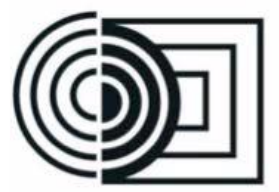
CINAHPA

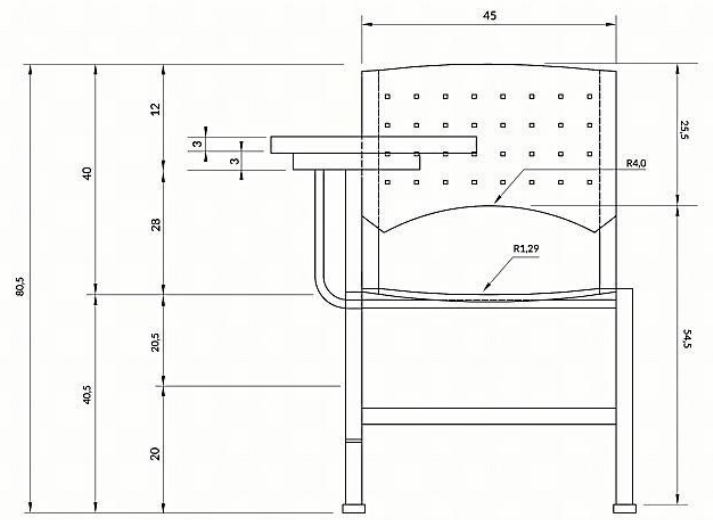

Figura 2: Dimensionamento do novo modelo de carteiras utilizado na universidade.

Fonte: Elaborado pelo autor da pesquisa.

Um mobiliário com medidas incorretas pode prejudicar de forma substancial à saúde dos usuários. $\mathrm{O}$ assento, por exemplo, se tiver uma altura muito elevada ou muito baixa, pode acarretar problemas à saúde do aluno, como aumento da compressão na parte posterior da coxa, caso o aluno não consiga encostar a planta dos pés no chão, causando assim formigamentos e dormências nos membros inferiores.

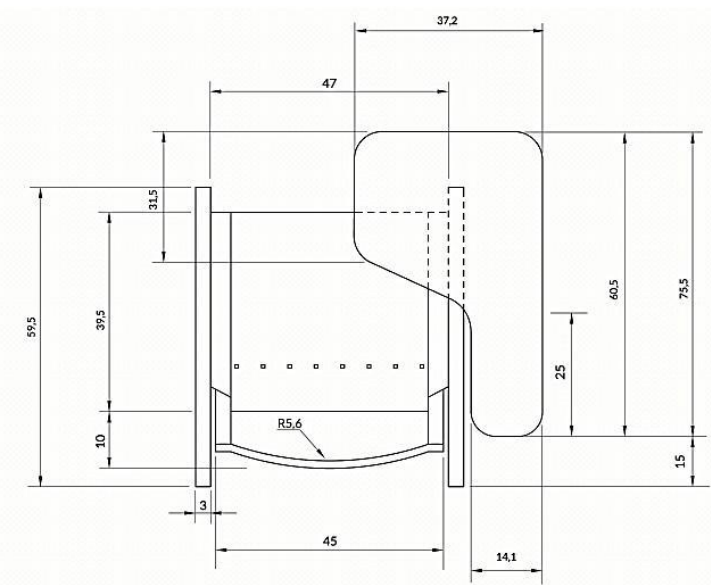

Figura 3: Dimensionamento do novo modelo de carteiras utilizado na universidade - Vista superior.

Fonte: Elaborado pelo autor da pesquisa.

A inclinação do encosto em relação ao assento da carteira de forma excessiva pode ocasionar problemas à saúde humana, dificultando os movimentos dos alunos para sentar-se e levantar-se das carteiras. É recomendado que o ângulo do encosto em relação ao assento seja entre $95^{\circ} \mathrm{e}$ $16^{\circ}$ Ergodesign - Congresso Internacional de Ergonomia e Usabilidade de Interfaces Humano Tecnológica: Produto, Informações Ambientes Construídos e Transporte

$16^{\circ}$ USIHC - Congresso Internacional de Ergonomia e Usabilidade de Interfaces Humano Computador

CINAHPA | 2017 - Congresso Internacional de Ambientes Hipermídia para Aprendizagem.

$105^{\circ}$. Visto que ângulos maiores que $110^{\circ}$ é recomendado para cadeiras de descanso.

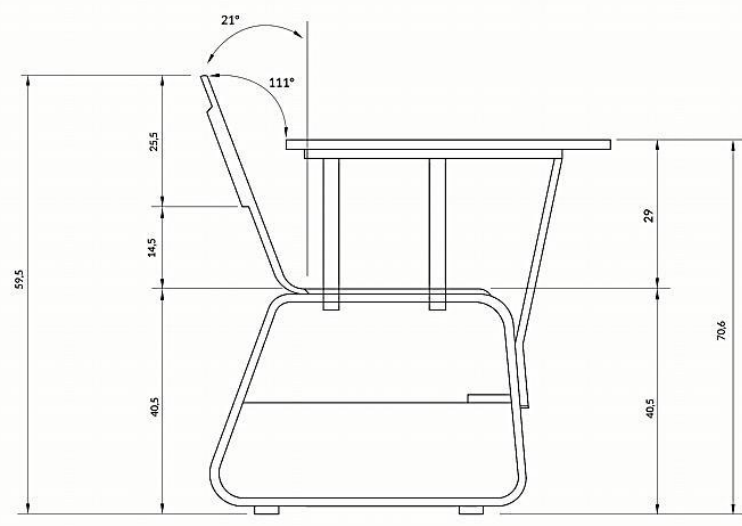

Figura 4: Dimensionamento do novo modelo de carteiras utilizado na universidade - Vista Lateral.

Fonte: Elaborado pelo autor da pesquisa.

\section{Apresentação e discussão dos resultados}

As pontuações finais do REBA são classificadas em categorias de acordo com a pontuação para melhor entendimento e interpretação dos resultados como visto na tabela 1 .

\begin{tabular}{|c|c|c|c|}
\hline Pontuação & Nível & Risco & Ação \\
\hline 1 & 0 & Inestimável & Intervenção não necessária \\
\hline $2-3$ & 1 & Baixo & $\begin{array}{c}\text { Intervenção pode } \\
\text { ser necessária }\end{array}$ \\
\hline $4-7$ & 2 & Médio & Intervenção necessária \\
\hline $8-10$ & 3 & Alto & Intervenção o quanto antes \\
\hline $11-15$ & 4 & Muito Alto & Intervenção imediata \\
\hline
\end{tabular}

Tabela 1: Pontuação Final REBA

Fonte: Desenvolvida pelo autor da pesquisa com base no método REBA.

Os participantes foram avaliados nos eventos que lhe são impostos ao assistir as aulas. Um dos eventos foi à prática de escrever ou ler os materiais dispostos na superfície da carteira (prancheta acoplada). Outro evento foi uso do Notebook utilizando também a superfície de apoio da carteira. Outro evento analisado foi o aluno assistindo aula sem a utilização de material de apoio, estando o mesmo apenas olhando para o quadro ou disperso em sala. Em todos os casos, os alunos deixavam sua bolsa ou mochila escolar de quatro maneiras sobre as coxas; ao lado do corpo 
$16^{\circ}$ USIHC - Congresso Internacional de Ergonomia e Usabilidade de Interfaces Humano Computador

CINAHPA | 2017 - Congresso Internacional de Ambientes Hipermídia para Aprendizagem.

apoiado sobre o assento da carteira; entre a coxa e as hastes que sustentam a prancheta; ou apoiada no chão.

Para melhor entendimento da análise utilizando o REBA para os alunos, foi possível compilar os resultados em uma tabela geral tabela 2 .

\begin{tabular}{|c|c|c|}
\hline \multirow{7}{*}{$\begin{array}{l}\text { Alunos de } \\
\text { ambos os } \\
\text { gêneros }\end{array}$} & Atividade & $\begin{array}{c}\text { Hemisfério } \\
\text { Corporal }\end{array}$ \\
\hline & \multirow{2}{*}{$\begin{array}{l}\text { Lendo textos ou } \\
\text { fazendo } \\
\text { anotações }\end{array}$} & Direito \\
\hline & & Esquerdo \\
\hline & \multirow{2}{*}{$\begin{array}{l}\text { Fazendo } \\
\text { uso do } \\
\text { notebook }\end{array}$} & Direito \\
\hline & & Esquerdo \\
\hline & \multirow{2}{*}{$\begin{array}{l}\text { Sem uso } \\
\text { de } \\
\text { material }\end{array}$} & Direito \\
\hline & & Esquerdo \\
\hline $\begin{array}{l}\text { Média da } \\
\text { Pontuação } \\
\text { Final }\end{array}$ & \multicolumn{2}{|c|}{$\begin{array}{c}\text { Diagnóstico REBA } \\
\text { Ação e Risco }\end{array}$} \\
\hline 4,05 & \multicolumn{2}{|c|}{$\begin{array}{c}\text { (Nível } 2 \text { - intervenção } \\
\text { necessária e } \\
\text { Risco Médio) }\end{array}$} \\
\hline 4,05 & \multicolumn{2}{|c|}{$\begin{array}{c}\text { (Nível } 2 \text { - intervenção } \\
\text { necessária e } \\
\text { Risco Médio) }\end{array}$} \\
\hline 6,0 & \multicolumn{2}{|c|}{$\begin{array}{c}\text { (Nível } 2 \text { - intervenção } \\
\text { necessária e } \\
\text { Risco Médio) }\end{array}$} \\
\hline 5,25 & \multicolumn{2}{|c|}{$\begin{array}{c}\text { (Nível } 2 \text { - intervenção } \\
\text { necessária e } \\
\text { Risco Médio) }\end{array}$} \\
\hline 3,57 & \multicolumn{2}{|c|}{$\begin{array}{c}\text { (Nível } 1 \text { - intervenção pode } \\
\text { ser necessária e } \\
\text { Risco Baixo) }\end{array}$} \\
\hline 3,32 & \multicolumn{2}{|c|}{$\begin{array}{c}\text { (Nível } 1 \text { - intervenção pode } \\
\text { ser necessária e } \\
\text { Risco Baixo) }\end{array}$} \\
\hline
\end{tabular}

Tabela 2: Média da pontuação final geral do diagnóstico REBA para os alunos de ambos os gêneros.

Fonte: Elaborado pelo autor da pesquisa.

Ao final da análise, foi possível constatar que dentre as seis pontuações para o diagnóstico, quatro foram de Nível - 2, requerendo uma intervenção necessária no mobiliário universitário, conotando assim Risco Médio à saúde do ser humano. Já as outras duas situações, são de grau menos elevado, Nível - 1 , deste modo uma intervenção pode ser necessária, identificado como de Risco Baixo à saúde humana.
Estando atento aos resultados adquiridos através do REBA, foi possível evidenciar que as carteiras universitárias analisadas não são adequadas para o uso do notebook, levando a entender que não foram projetadas com o intuito de atender a essa necessidade nas salas de aulas atuais, mesmo sendo uma atividade rotineira na era digital. Com os avanços tecnológicos, cada vez mais os alunos estão substituindo os cadernos por computadores e outros equipamentos eletrônicos nas salas de aula. O mobiliário universitário precisa acompanhar essas evoluções, e atender as demandas da sociedade atual. A partir dessa análise, foi notado que as carteiras não atendem o uso para esse fim, onde se consta a necessidade que seja revisto com urgência a projetação desse mobiliário levando em consideração a Ergonomia.

Devido à falta de adequabilidade das carteiras, os alunos precisam assumir posturas inadequadas, como inclinação acentuada da coluna vertebral e pescoço, torção e inclinação no tronco, desvio ulnar acentuado no punho esquerdo e direito a depender se é destro ou canhoto. Algumas lesões de riscos à saúde podem acometer os alunos ao utilizarem o notebook nessa carteira, como aumento da compressão na parte posterior da coxa, dores na coluna vertebral, aumento na compressão intradiscal, tendinites, bursites, epicondilites e síndromes do túnel do carpo, entre outras. Ao término da análise foi possível perceber que o mobiliário atual não está adequado para o uso dos alunos, sendo prejudicial à saúde e é preciso ser revista essa substituição.

\section{Conclusão e considerações finais}

Seguindo as diretrizes do método REBA, foi possível identificar posturas inadequadas impostas pelas carteiras aos alunos, como inclinação do tronco e pescoço de forma acentuada ao utilizar o notebook sobre a prancheta acoplada, desvio ulnar em ambos os punhos a depender da posição em que o notebook se encontrava. Ficou evidente que as carteiras não são adequadas para o uso no notebook e se torna ainda mais prejudicial à saúde dos alunos com estaturas mais elevadas, que 
$16^{\circ}$ Ergodesign - Congresso Internacional de Ergonomia e Usabilidade de Interfaces Humano Tecnológica: Produto, Informações Ambientes Construídos e Transporte

$16^{\circ}$ USIHC - Congresso Internacional de Ergonomia e Usabilidade de Interfaces Humano Computador

CINAHPA | 2017 - Congresso Internacional de Ambientes Hipermídia para Aprendizagem.

ultrapassem $1,80 \mathrm{~m}$.

Outros problemas que estão relacionados ao uso da carteira é o aumento na compressão intradiscal, compressão na parte posterior da coxa e abdução do membro superior, ao apoiá-lo sobre a prancheta, sendo mais acentuado para pessoas com estaturas mais baixas. Por não ser projetado pensado no usuário, o mobiliário ocasiona posturas inadequadas para os alunos.

Os resultados apanhados conotam que a troca do mobiliário não tendo a Ergonomia como critério para compra e fazendo a escolha de forma empírica, não foi assertiva, pois a análise da postura nos revela inadequações projectuais do mobiliário. Vale ressaltar que o investimento financeiro gasto pela Instituição para aquisição do mobiliário foi equivocado, sendo um gasto desnecessário e aplicado erroneamente. Ao término da pesquisa, foi possível perceber a necessidade da Instituição em dispor de mobiliários com tamanhos diferentes, para assim atender melhor aos alunos que possuem estaturas diversas. Onde os alunos podem escolher qual o mobiliário mais se adeque a sua estatura.

\section{Bibliografia}

BERGMILLER, K. H. et al. Ensino fundamental: mobiliário escolar. Brasília: FUNDESCOLA MEC, 1999.

BRACCIALLI, L. M. P. Postura corporal: orientação para educadores. 125 f. Dissertação (Mestrado em Educação Física) - Faculdade de Educação Física, Universidade Estadual de Campinas, Campinas, 1997.

CARVALHO, F.H.T. Mobiliário escolar 2001. Acesso em 01 de setembro de 2016. Disponível em: www.tvbrasil.com.br/salto.

CHAFFIN, D. B.; ANDERSSON, G. B. J.; MARTIN, B. J. Occupational biomechanics. 4. ed. New Jersey: Wiley, 2006.

COUTO, Hudson de Araújo. Ergonomia aplicada ao trabalho. Manual técnico da máquina humana. Belo Horizonte: Ergo Editora, 1995.

DIEGO-MÁS, J. A.; CUESTA, S. A. NIOSH (NATIONAL INSTITUTE for OCCUPATIONAL SAFETY and HEALTH). Disponível em: www.ergonautas.upv.es. Acesso em: 21/12/ 2016, 22:39.

IIDA, I.; Ergonomia:Projeto e Produção. São Paulo, Edgard Blucher, 2005.

KENDALL, F. P.; MCCREARY, E. K.; PROVANCE, P. G.; RODGERS, M. M.; ROMANI, W. A. Músculos: provas e funções. 5. ed. São Paulo: Manole, 2007.

MARQUES, N. R.; HALLAL, C. Z.; GONÇALVES, M. Características biomecânicas, ergonômicas e clínicas da postura sentada: uma revisão.Fisioterapia e Pesquisa, 2010.

NUNES F. P. et al. Special education teacher's perception of the educational desk: a survey report. International Journal of Instructional Media, 1985.

REPUANO GUIDALLI, Cláudia Rocha. Diretrizes para o projeto de salas de aula em universidades visando o bem-estar do usuário. Dissertação de Mestrado - apresentada ao Programa de Pós-Graduação em Arquitetura e Urbanismo da Universidade Federal de Santa Catarina, 2012.

RICHARDSON, V. Tempo e espaço. In: ARENDS, R. I. Aprender a ensinar. Lisboa: McGrawHill, 1997.

SANOFF, Henry. School building assessment methods. 2001. Disponível em:

$<$ http://www.edfacilities.org/pubs/sanoffassess.pdf >. Acesso em: 15 de outubro 2016, às 23:35.

THARIQ, M.G.; MUNASINGHE H.P.; ABEYSEKARA J.D. Designing chairs with mounted desktop for university students:

Ergonomics andcomfort. International Journal of Industrial Ergonomics, 2010. 